\title{
University Students in Southwestern Spain Digital Competences
}

\author{
Olga Moreno-Fernández ${ }^{1, *}$, Pilar Moreno-Crespo ${ }^{2}$, and Coral I. Hunt-Gómez ${ }^{1}$ \\ ${ }^{1}$ Faculty of Education Sciences, University of Seville, Spain. \\ ${ }^{2}$ Faculty of Education Sciences, University of Huelva, Spain.
}

\begin{abstract}
The European Higher Education Area has marked a milestone in Higher Education. Consequently, teaching methodologies have experienced several transformations and their focus has turned to the incorporation of ICT in socio-educational environments. Thus, it can be stated that digital competences development is a paramount element for university students' training, as they need to be digitally competent. This study explores the degree of knowledge and training about digital competences that students pursuing undergraduate or postgraduate studies in Educational Sciences have. The questionnaire "University Student' Basic Digital Competences 2.0" (COBADI/ Trademark 2970648) was applied to students of Early Years Education, Primary Education, Social Education and postgraduates of the Master's Degree in Secondary Education from the Universities of Seville and Huelva (Southwestern Spain). Results show that digital competence in university students needs to be improved. There is, therefore, a definite need for transversal and organized training allowing students to master digital contexts efficiently.
\end{abstract}

\section{Introduction}

The European Higher Education Area (EHEA) has marked a milestone in Higher Education. Consequently, teaching methodologies have experienced several transformations and, in many cases, their focus has turned to the incorporation of ICT (Information and Communication Technologies) in socio-educational environments. If ICT is to be incorporated into Higher Education, several digital competences allowing students, as well as their educational institutions, to manage software and hardware and other digital resources are needed ([1], [2], [3], [4]). Thus, it can be stated that digital competences development is a paramount element for university students' training, as they need to be digitally competent.

\section{Method}

This study explores the degree of knowledge and training about digital competences that students pursuing undergraduate or postgraduate studies in Educational Sciences have. To

* Corresponding author: omoreno@us.es 
do so, an exploratory, quantitative, transversal and non-probabilistic study has been carried out ([5], [6]). Subjects were undergraduate students of Early Years Education, Primary Education, Social Education and postgraduate students of the Master's Degree in Secondary Education from the Universities of Seville and Huelva (Southwestern Spain). The questionnaire "University Student' Basic Digital Competences 2.0" (COBADI/ Trademark 2970648) was applied and data were analysed using Statistical Package for the Social Sciences (version 24, IBM SPSS).

\section{Results}

$90.09 \%$ of the participants in the study were women and $9.91 \%$ men. The ages of the participants are varied, however the vast majority of them were aged 22-26 (53.60\%) and 17-21 (36.94\%) (Figure 1).

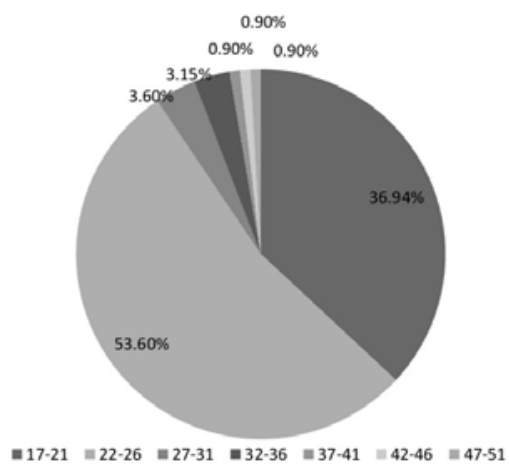

Fig. 1. Age of the participants.

Regarding the studies of the participants, $43.24 \%$ were students of the Degree in Social Education, 34.23\% were students of the Degree in Early Years Education, 13.51\% were students of the el Master's Degree in Secondary Education, and 9.01\% were students of the Degree in Primary Education (Figure 2). 68.02 of the subjects were students of the University of Huelva and $31.98 \%$ of the University of Seville.

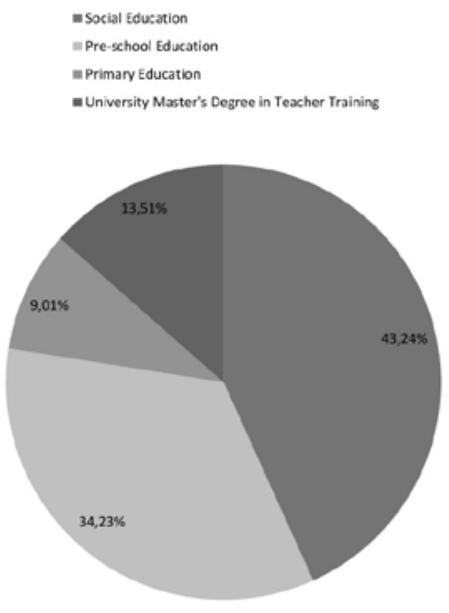

Fig. 2. Studies of the participants. 
Regarding the use of ICT, the two most used electronic devices were the following: mobile phone $(94.1 \%)$ and laptop y $(92.3 \%)$. Other devices appeared with lower percentages tablet $(21.2 \%)$, desktop computer $(7.7 \%)$, e-book $(1 \%)$, television $(0.5 \%)$ or printer $(0.5 \%)$ (Figure 3$)$. Subjects were able to mark all the options they considered appropriated.

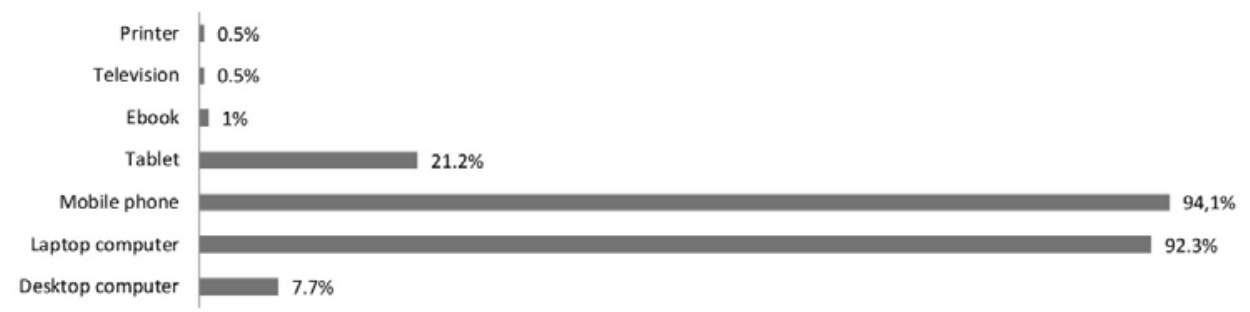

Fig. 3. Most used electronic devices by university students.

Regarding their Internet connection, $98.2 \%$ of the subjects state that they have connection on their mobile phone, $96.8 \%$ in the lap-top, $34.7 \%$ in the Tablet, $22.1 \%$ in the computer, and $1 \%$ in their television (Figure 4). E-book and printers do not appear in this list. Subjects were able to mark all the options they considered appropriated.

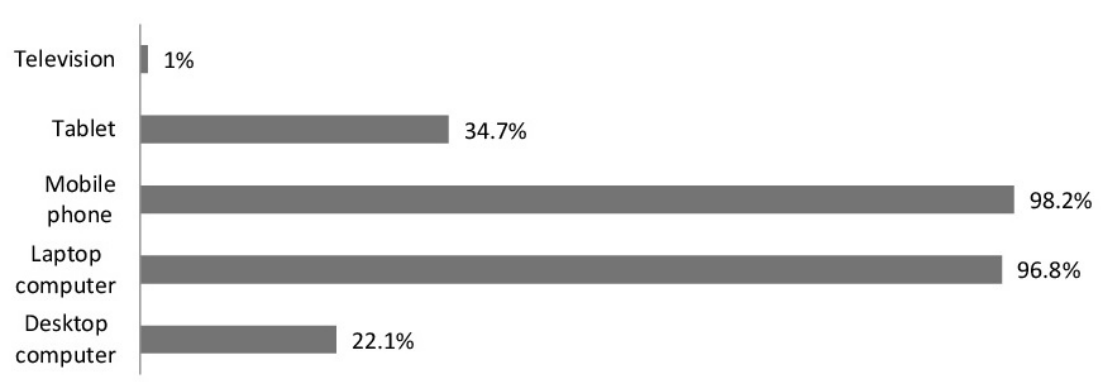

Fig. 4. Most used electronic devices with internet connection by university students.

Regarding the amount of time they have availability of internet connected electronic devices, $86 \%$ of the subjects stated that they are connected all day long, $24.3 \%$ of the students also get connected in public spaces which offer free Wi-Fi (Figure 5). Subjects were able to mark all the options they considered appropriated.

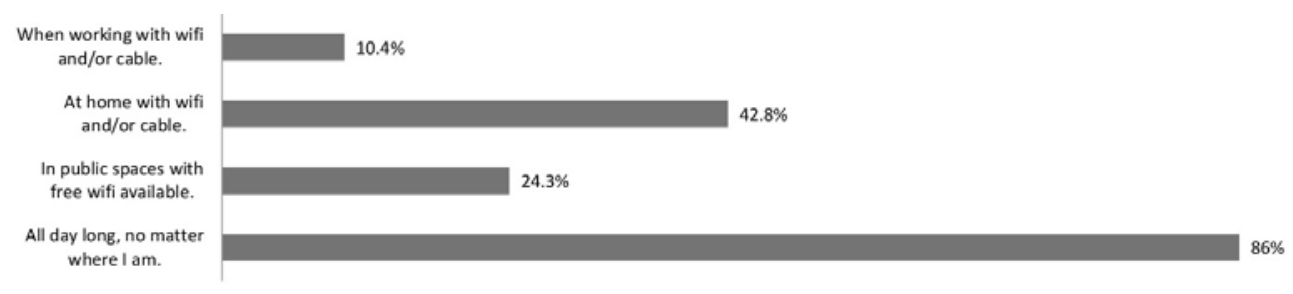

Fig. 5. Most ranked places were university students get connected. 
The resources most frequently used by students when connected to the Internet is chatting using the App WhatsApp (88.7\%), followed by using search engines like Google (77\%), using social networks like Facebook (77\%) and consulting the e-mail (71.6\%), and using platforms like YouTube (64.4\%) (Figure 6). Subjects were able to mark all the options they considered appropriated.



Fig. 6. Most frequently used resources by the university students.

When describing the academic use of electronic devices made by university students, $93.2 \%$ of subjects stated to use mainly the laptop, $32 \%$ of the mobile phone and, only $9.9 \%$ use the tablet and $4.1 \%$ the desktop computer (Figure 7 ).

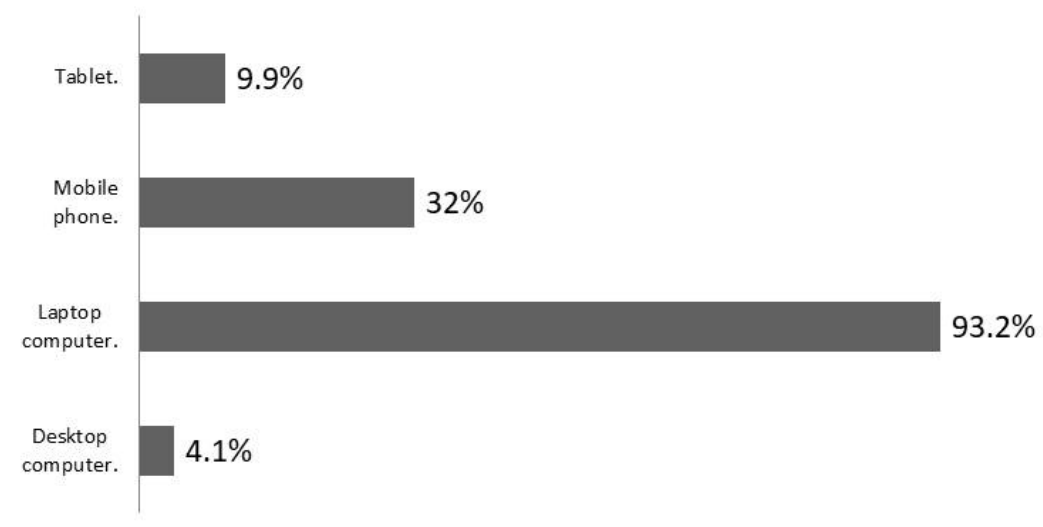

Fig. 7. Most used electronic devices by university students for academic purposes.

The use made by university students with academic purposes of these electronic devices can be ranked as follows: $91.9 \%$ using to the virtual platform of the subjects, $87.8 \%$ using search engines like, $69.4 \%$ using the e-mail, $27.5 \%$ communicating apps such as WhatsApp, $11.7 \%$ using platforms like YouTube, 5\% using social networks such as Facebook (Figure 8). Subjects were able to mark all the options they considered appropriated. 


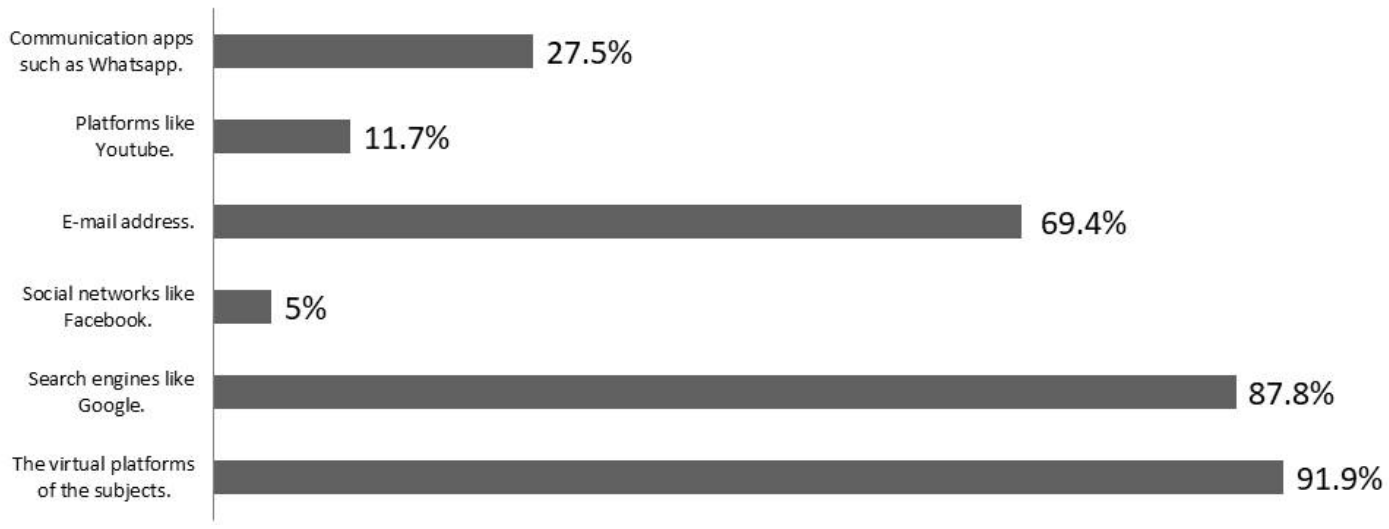

Fig. 8. Most used devices for academic purposes by university students.

When describing the COBADI items, it must be highlighted that $60.4 \%$ strongly agree and $32.9 \%$ showed some agreement with the statement 'I can communicate with other via email'. 5\% showed some disagreement and 1.8\% strongly disagree. Another tool considered important to connect people were instant massaging apps. $74.8 \%$ of the subject completely agreed with the statement, $16.2 \%$ showed some agreement, 5.9\% somehow disagreed and $3.2 \%$ strongly disagreed. $63.1 \%$ considered social networks (Twitter, Facebook, Ning among others) as a mean of communication, $27.5 \%$ somehow agreed with that statement, $6.8 \%$ somehow disagreed and $2.7 \%$ strongly disagreed. Students were asked to state their degree of agreement to the use of professional networks like Linked-in or Xing . Only $11.3 \%$ of students showed strong agreement. $38.3 \%$ showed some agreement, $27.5 \%$ showed some disagreement and $23 \%$ strongly disagreed (Figure 9 ).

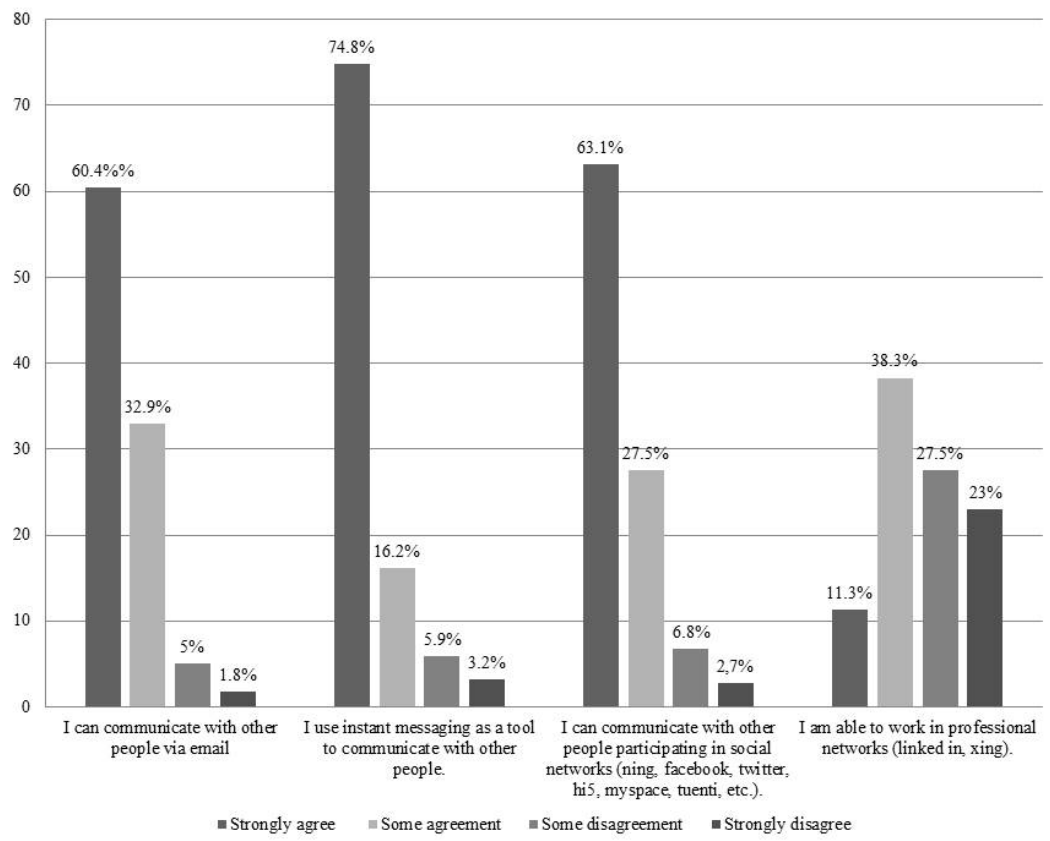

Fig. 9. Digital Communication Competences. 
In regard to the item 'I know how to use wikis' like Wikipedia or aulawiki21', $27.9 \%$ of the subjects strongly agreed, 50.9\%showed some agreement, $17.6 \%$ showed some disagreement and $3.6 \%$ strongly disagreed. As to the item 'working with documents in the web (google drive, skydrive)' $55.9 \%$ of the subjects strongly agreed, $28.8 \%$ showed some agreement, $12.2 \%$ showed some disagreement and $3.2 \%$ strongly disagreed. Thus, it can be stated that $84.7 \%$ of the university students use this king of tools to have their tasks updated. Regarding the item 'I am able to organize, analyse and synthetize information through concept maps using some social software tools (cmaptool, mindomo, text 2 mindmap...)' $28.8 \%$ of the subjects strongly agreed, $27.9 \%$ showed some agreement, $26.1 \%$ showed some disagreement and $17.1 \%$ strongly disagreed. Participants were asked about their degree of agreement to the statement 'I feel competent to work with social software tools to help me to analyse and/or navigate through content included in blogs (wordle, Tagxedo...)". $39.6 \%$ of the subjects showed some disagreement and $31.1 \%$ strongly disagreed (Figure 10)

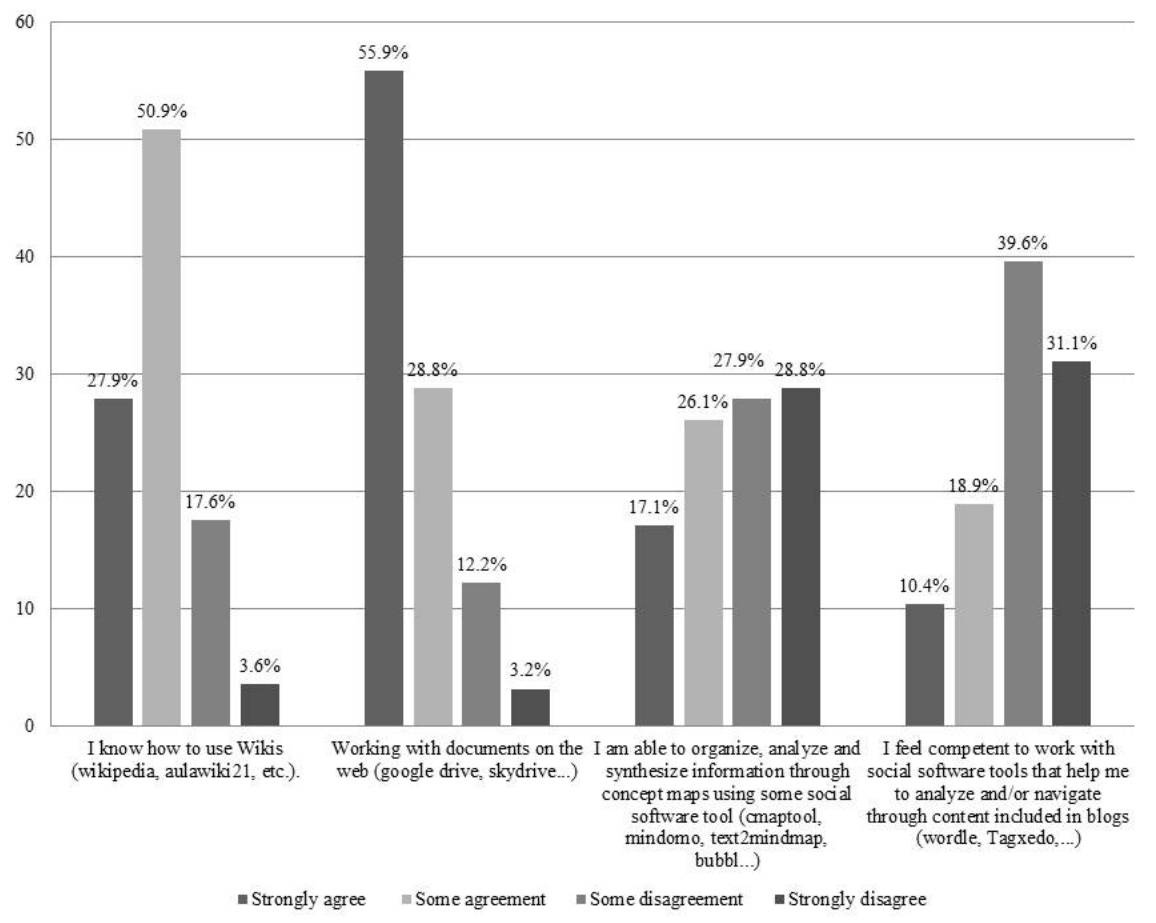

Fig. 10. Digital Use Competences.

\section{Conclusion}

Results indicate that a high percentage of university students use e-mail and instant massaging as a way of communication with others. The use or social networks as a mean of communication is also significant. Subjects regard themselves as competent in the use of Internet search engines and highly competent when working with documents on line. However, participants acknowledged their lack of competences regarding information organization, analysis and synthesis when working with conceptual maps included in social software tools. 
Results show that digital competence in university students needs to be improved. There is, therefore, a definite need for transversal and organized training allowing students to master digital contexts efficiently. If the requisites of the European Higher Education Area are to be fulfilled, digital competences need to be in the centre of the educational agenda.

\section{References}

1. UNESCO, Enfoque estratégico sobre TIC en educación en América Latina y el Caribe. Oficina Regional de Educación para América Latina y el Caribe (OREALC/ Unesco Santiago) (2013)

2. E. Vázquez-Cano, E. López-Meneses, E. Fernández-Márquez, Concept Mapping for Developing Competencies in European Higher Education Area, Inter. Journal of Humanities and Social Sci., 3 (15) (2013)

3. L. Johnson, S. Adams Becker, M. Cummins, V. Estrada, A. Freeman, C. Hall, NMC Horizon Report: 2016 (Higher Education Edition, 2016)

4. E. Vázquez-Cano, V. Marín-Díaz, G.A. Maldonado-Berea, E. García-Garzón, E., La competencia digital del alumnado universitario de Ciencias Sociales desde una perspectiva de género, Prisma Social. Revista de Investigación Social, 19, (2017)

5. M. Canales, M, Metodologías de investigación social (Santiago, Lom Edicione, 2006)

6. R. Hernández, C. Fernández, P. Baptista, Metodología de la investigación, (México, McGraw-Hill, 2006) 